\title{
Vuelve el tango: "Tango argentino" y las narrativas sobre el resurgimiento del baile en Buenos Aires
}

\author{
Carlos Hernán Morel
}

RMA

Antropología Social
CONICET, Instituto de Ciencias Antropológicas, Facultad de Filosofía y Letras, Universidad de Buenos Aires, Argentina. E-mail: hermorel@hotmail.com

\begin{abstract}
Resumen
En la actualidad, el baile de tango en Buenos Aires ha cobrado un renovado valor en tanto práctica local, del mismo modo que se ha convertido en un poderoso recurso para la promoción económica y el desarrollo turístico de la ciudad. En este artículo analizamos algunas narrativas -reproducidas por milongueros, bailarines y allegados al tango- que tratan sobre cómo el tango "volvió" a ser una práctica culturalmente legítima en la ciudad a partir de la década del '80. Sobre la base de este proceso de resurgimiento del tango bailado, abordamos la construcción de un relato dominante vinculado a un espectáculo denominado "Tango Argentino". Exploramos de qué modo este relato es objeto de legitimación y disputa en el presente, al tiempo que observamos las relaciones dialógicas que establece con distintas narrativas y cómo ello se encadena con enunciaciones históricas o anteriores. A partir de estas construcciones narrativas sobre el presente y el pasado del tango problematizamos los sentidos en pugna vigentes en torno a la práctica del baile en Buenos Aires.
\end{abstract}

Palabras clave: tango; baile; narrativa; relatos sobre el pasado.

Tango is back: "Tango Argentino" and the narratives about the comeback of the dance in Buenos Aires

\begin{abstract}
At present, tango dance in Buenos Aires has aroused renewed interest as a local practice and become a valuable resource for economic development and tourism promotion in the city. In this paper we will analyze the narratives -reproduced by milongueros, tango dancers and those close to tango- which explain why tango "has made a comeback" to be a culturally legitimate and recognized practice in the city from the 80s onwards. On the basis of this process of revival of tango danced, we will address the construction of a dominant story linked to a show called "Tango Argentino". We will explore how this story today is the subject of legitimacy and dispute, and will observe the dialogical relations established with different narratives and how they interact with historical or previous utterances. From these tango narrative constructs about past and present, we will question the confrontation of meanings around the practice of dancing in Buenos Aires.
\end{abstract}

Key Words: tango; dance; storytelling; stories about the past.

En este trabajo nos proponemos analizar algunas narrativas relacionadas con el resurgimiento del tango como práctica bailable en Buenos Aires. Me interesa explorar las lógicas de reproducción social que operan en la construcción de relatos asociados a la revalorización del tango-danza. En particular, abordamos la construcción de un relato que ubica a un espectáculo escénico llamado "Tango Argentino", como un hito que marcó un antes y un después en la revitalización del género a partir de la década del '80. El espectáculo de "Tango Argentino" fue exhibido en las principales capitales y países del mundo y se destacó por agrupar en una misma compañía a destacadas figuras del tango porteño; fundamentalmente bailarines-milongueros, cantantes y músicos. Como veremos más abajo, el relato en torno al espectáculo de "Tango Argentino" enfatiza su gran "éxito" y repercusión basándose en el atractivo que ejerció éste sobre un público extranjero en tiempos en que el tango, por diversas razones, representaba una actividad artístico/ cultural con muy poco interés.

En líneas generales, he escogido referirme a este suceso de "Tango Argentino" dado que el mismo nos permite desarrollar una serie de reflexiones que incumben a las relaciones que se establecen entre prácticas verbales o narrativas y prácticas referidas al baile de tango propiamente. En primer lugar, intentaré mostrar cómo la problematización de estas narrativas nos permite afrontar algunos supuestos subyacentes que por lo general han pasado inadvertidos en relación a las transformaciones locales asociadas al baile de tango. En segundo lugar, veremos de qué modo este relato referido a un espectáculo internacional de tango tiende a invisibilizar distintos acontecimientos y procesos culturales que se 
produjeron a nivel local en el contexto de la década del '80. A través del análisis crítico de las narrativas de un conjunto artistas, bailarines, milongueros, profesores y actores diversos allegados al tango, sugeriremos que las construcciones discursivas referidas al resurgimiento del tango en Buenos Aires evidencian diferentes visiones y posiciones en conflicto. Advertiremos que estas prácticas narrativas sobre sucesos pasados recientes ponen de manifiesto una tensión y una disyuntiva entre una concepción dominante, institucionalizada y unitaria frente a otras perspectivas que se ubican como fragmentarias, subordinadas y, en cierto modo, resistentes.

Como parte de una investigación etnográfica más amplia, en la que examino los procesos de activación patrimonial del tango-danza en Buenos Aires (Morel 2011b), a partir del año 2006 comencé a realizar observación participante en distintos ámbitos en los que se enseña, aprende y ejecuta el baile social del tango ${ }^{1}$. En particular, el presente artículo está producido sobre la base de los siguientes tipos de información: mis notas y experiencias personales de campo; los relatos de bailarines-milongueros y productores que participaron de "Tango Argentino"; publicaciones de periodistas especializados en esta temática; y entrevistas y conversaciones informales con personas que comenzaron a relacionarse con los circuitos y espacios de baile de tango en el contexto de la década del '80.

Originalmente el campo de estudio de las narrativas, a través del análisis de los mitos y los relatos orales encarados por la antropología y las investigaciones de folklore, se preocupó en abordar a éstas a modo de textos fijos que permitían revelar información sobre una cultura particular, su lenguaje o "mentalidad primitiva" (Langdon 1999:14). Esta perspectiva clásica que ubicaba a las narrativas tradicionales como algo prístino y homogéneo, señala Langdon, "...ha sido una de las grandes fallas en los estudios de folklore en general, en la cual la noción de tradicional es aplicada a la narrativa que representa más fielmente su versión original y esta versión es considerada más verdadera y auténtica que las otras" (1999: 17, nuestra traducción). En este sentido, gran parte de los estudios y debates contemporáneos han criticado esta concepción que situaba a las narrativas - del mismo modo que a las diversas formas de habla- como expresiones independientes o aisladas de los contextos de producción particulares. A partir de una nueva orientación en la investigación, a comienzos de la década del `70 tanto la sociolingüística como la etnografía del

\footnotetext{
1 Para ello asistí frecuentemente a diferentes clases, salones de baile y milongas porteñas a las que concurren personas de distintas edades, mayoritariamente heterosexuales. En los primeros años me inicié como alumno, tomando clases de tango en la zona del centro de la ciudad, con diferentes profesores/as que enseñan el llamado estilo "milonguero". Luego de dos años, y habiendo avanzado en el aprendizaje del baile, empecé a ir a clases y prácticas que se ubican en la zona norte de la ciudad, en las que se enseñan otras formas de baile denominadas como "tango salón".
}

habla llamaron la atención sobre el papel del lenguaje y la comunicación como parte de la vida social (Hymes 1986). Estas perspectivas propugnaron que la producción de sentido a través de las narrativas no opera como mero "reflejo" del mundo sino que estaría ajustada a situaciones sociales, históricas y culturales específicas, al tiempo que consideraron que las diversas formas de habla emergen de una praxis social que esta enlazada a actores socioculturales que la constituyen (Ochs 2000; Rosaldo 1989).

Por otra parte, y de modo convergente, los estudios de Bajtín advirtieron el carácter dialógico e históricamente producido de los géneros discursivos. Para este autor los hablantes de una lengua producen enunciados sobre la base de una experiencia histórica por lo que en este proceso tienden a "arrastrar" sentidos anteriores provenientes de otros contextos, situaciones y usos sociales, y así:

"El objeto del discurso de un hablante, cualquiera que sea el objeto, no llega a tal por primera vez en este enunciado, y el hablante no es el primero que lo aborda. El objeto del discurso, por decirlo así, ya se encuentra hablado, discutido, vislumbrado y valorado de las maneras más diferentes; en él se cruzan, convergen y se bifurcan varios puntos de vista, visiones del mundo, tendencias (...) su discurso se convierte inevitablemente en un foro donde se encuentran opiniones de los interlocutores directos $(\ldots)^{\prime \prime}(1992:$ 284).

Dado que como venimos señalando, en ocasiones las narrativas presuponen enraizadas conexiones históricas con contenidos semánticos e imaginarios culturales particulares, en lo que sigue nos interesa abordar un aspecto singular que retrata la poética del tango rioplatense.

\section{La idea de "volver" en el tango}

"Aquí, mis sueños siguen esperando, la música de aquí se llama tango. Tango es la emoción de regresar al punto cardinal..."2

"Un día volvió a sus pagos la sociedad lo admiró porque en París lo aclamaron. Ahora sí que es un señor!" 3

Podríamos decir que en el tango rioplatense la idea de "volver"4 aparece como un tópico característico o

\footnotetext{
2 "Prólogo para mi Argentina", poema de Juanca Tavera recitado por Rubén Juarez en su disco El Álbum Blanco (2002).

3 "Tango", letra de Juan Carlos Cáceres de su disco Murga Argentina (2005)

4 Usualmente, el tópico metafórico "volver" alude a alguna cosa, en-
} 
arquetípico del género. Esto es, a través de un extenso repertorio poético-musical, las letras de los tangos frecuentemente reafirman la necesidad o el deseo de estar volviendo al "punto cardinal". Ciertamente, esta idea de retorno cíclico al punto de origen no es exclusiva del tango dado que toda forma de pensamiento mítico apela, parafraseando a Lévi-Strauss, a una "búsqueda del tiempo perdido" (1987: 227). En el caso del tango rioplatense, ello puede rastrearse en numerosas y variadas modalidades narrativas que se han ido recreando en distintos momentos históricos. Por una parte, su expresión más difundida se manifiesta a través de la poética verbal de las canciones, las letras y los intérpretes característicos de este género ${ }^{5}$. Por otra parte, esta metáfora del volver, también sirvió de inspiración para una gran cantidad de películas argentinas en las que el tango como expresión popular e identitaria ocupó un lugar central ${ }^{6}$.

Al mismo tiempo, existe una abundante literatura proveniente del ámbito académico (estudios históricos, folklóricos y antropológicos) que ha establecido algunos diálogos significativos para el análisis de esta temática del volver en el tango que venimos señalando. Esta literatura ha propuesto un marco interpretativo para la comprensión de las transformaciones del tango a lo largo de su proceso histórico, buscando explicar las razones que han permitido la legitimación cultural de este género popular a partir de la primera década del siglo XX. En cuanto a los estudios históricos, ya desde la década del '30 se afirmó lo que algunos historiadores actuales han denominado una "versión canónica"7 referida a los orígenes del tango. Esta versión consolidó la idea de un proceso de legitimación cultural del género sobre la base

tidad o persona que aspira retornar a un presunto punto de partida $u$ origen -que puede estar referido al tango mismo, al amor, a la juventud, al barrio, etc.- o que, en todo caso, busca recobrarse de una situación de pérdida o extravío. Sobre este tópico, véase Pelinski (2000).

${ }^{5}$ Para ejemplificar algunos signos de este imaginario poético podemos remontarnos al mismo Carlos Gardel y su famosa interpretación del tango Volver (1935, con letra de Alfredo Le Pera) allí dice "Yo adivino el parpadeo/ de las luces que a lo lejos/ van marcando mi retorno..."; pasando luego por las palabras de Aníbal Troilo, cuando en su obra Nocturno a mi barrio (1968) afirma "Alguien dijo una vez que yo me fui de mi barrio./ Cuando!? Pero Cuando!?/ Si siempre estoy llegando...". Más tarde, cantautores contemporáneos como Jorge "Alorsa" Pandelucos interpretarán canciones como Vuelve el tango: "Me leyó una gitana en la borra del café que vuelve el tango/ Se escapó de enredadas partituras/ Los que no lo conocen lo pedían/ Alguien lo dio por muerto, qué locura!, si era siesta, nomás,/ La que dormía."

${ }^{6}$ En este sentido distintas películas, que van desde los mismos comienzos del cine argentino hasta la actualidad, establecen una trama narrativa muy semejante. Particularmente, algunos films narran los procesos de transformación del tango a partir de los viajes, los desplazamientos y los "ascensos" del mismo (p.e. de los arrabales al centro de la ciudad o de Buenos Aires a París). Es el caso de muchas películas, algunas incluso protagonizadas por Carlos Gardel, entre las que esta Melodía de arrabal (1932), del mismo modo que otras producciones fílmicas como Tango! (1933), La vida es un tango (1939), El tango vuelve a París (1948) o más recientemente El exilio de Gardel (1986) e incluso, en algunos aspectos, La lección de tango (1996).

7 Según Cibotti (2009) esta versión fue plasmada y difundida, entre otros, por Héctor y Luís Bates en el año 1936. de un itinerario que incluye los comienzos prostibularios y en los suburbios "de bajo fondo" de la danza del tango, el subsiguiente "triunfo" en París (Francia), y su consecuente retorno y consagración en Buenos Aires a partir de su aceptación por las clases altas porteñas ${ }^{8}$ (Cibotti 2009: 44). A su vez, esta misma versión que aparece como mito fundacional del género, años después, fue recobrada por el musicólogo y folklorista argentino Carlos Vega. Por su parte, este autor caracterizó la historia de "ascenso del tango en la Argentina" en relación a la "aceptación" y al "depuramiento" del baile que aconteció a partir de su inserción en los salones de París luego de 1910 (Vega 2007: 150). Mucho más recientemente la antropóloga Marta Savigliano (1995), abordó algunos aspectos de este relato vinculado al proceso de aceptación del baile de tango por la elite porteña a comienzos de siglo XX, señalando cómo este proceso cultural estuvo marcado y configurado trasnacionalmente por las relaciones centroperiferia entre Europa y Argentina ${ }^{9}$.

En resumen, sobre la base de lo hasta aquí expuesto podríamos decir que, a través de distintas modalidades narrativas se ha reiterado, reproducido y abalado una versión canónica que asume y naturaliza la idea de que el tango requiere para legitimarse localmente de un viaje de ida y vuelta consagratorio. Así, a semejanza de los motivos que organizan a los cuentos folklóricos (Chertudi 1967) esta versión parece reforzar los rasgos de una misma "trama", entendiendo por trama la manera en que ciertos actos se entrelazan para crear un esquema coherente que gira en torno a un suceso excepcional (Ochs 2000: 283). A nuestro entender, la secuencia de episodios que caracterizan a la trama de este relato puede sintetizarse del siguiente modo: a- inicialmente remite a circunstancias conflictivas en las que el tango refleja una situación de devaluación, prohibición o extravío; b- un itinerario de partida hacia tierras lejanas - generalmente Europa- en donde éste es finamente reconocido, valorado y consagrado; y c- culminando con un regreso a su presunto lugar de origen, siendo la ciudad de Buenos Aires el certificado de identidad necesario para el logro de un final promisorio.

Ahora bien, a continuación nos interesa reflexionar en la siguiente problemática: ¿Qué versiones en la actualidad se construyen en torno a este tópico común y recurrente en el tango asociado a la temática de su regreso? Más

\footnotetext{
${ }^{8}$ No obstante, cabe destacar que esta versión comenzó a ser objeto de debate en algunas investigaciones históricas que abordan las condiciones de participación y circulación social del tango a comienzos del siglo XX. Ver Lamas y Binda 2008; Cibotti 2009.

${ }^{9}$ Asimismo, Florencia Garramuño (2007: 150) en su libro Modernidades Primitivas analizó los primeros "viajes de exportación" del tango a París, observando cómo el tango se ubica a modo de un intercambio mercantil (un producto cultural-artístico nacional) que se supedita a las demandas de danzas exóticas vigentes en Europa. La autora destaca que estos viajes de artistas argentinos al extranjero implican una exportación regida por beneficios económicos, en la que los artistas ganan no solo dinero sino también fama a partir del prestigio de haber triunfado en Europa.
} 
específicamente ¿Qué narrativas y sucesos significativos aparecen coligados con los procesos de transformación y revitalización del baile de tango en la actualidad en Buenos Aires?

\section{El baile de tango y los milongueros a comienzos de la década del ' 80}

Tras el fin de la última Dictadura Militar en la Argentina (1976-83) se evidenciaba un efecto dramáticamente negativo en las actividades ligadas al tango así como un marcado retroceso tanto en la popularidad como en la creatividad de este género en Buenos Aires. Como resultado de esta retracción social y artística que experimentaba el tango, tras la vuelta al gobierno constitucional en el año 1983 se extendía un imaginario sobre el tango que lo vivenciaba como anacrónico, estancado y hundido inexorablemente en el pasado. Un historiador al respecto afirmó "Después de una década muy dura para el tango -posiblemente la más dura de todas-, los años ‘80 marcan muy lentamente y luego de modo acelerado, la recuperación tanguística" (Pujol 1999: 340). En este marco histórico, dominaba sobre el tango una mirada y un imaginario nostálgico que lo invocaba como un "vestigio" cultural del pasado en progresiva desaparición. Particularmente, un film de la época como El exilio de Gardel (1986) de Fernando "Pino" Solanas, destacó algunos signos de este imaginario que vinculaba al tango con un pasado mítico, sumado al exilio político de la última dictadura que diseminaría a los tangueros (músicos, bailarines, cantantes), así como a muchos argentinos, por el mundo (Pelinski 2009: 108).

En lo que refiere a la práctica del baile, a comienzos de la década del '80 continuaban funcionando escasas milongas ${ }^{10}$ o salones de baile de tango y tan solo algunos pocos y ocultos grupos de milongueros aficionados y profesionales, en su mayoría gente de edad mayor, lo seguían bailando y enseñando en la ciudad. Por su parte, la sensación de muchos de estos milongueros de edad avanzada era que el baile de pista y social que ellos ejecutaban se estaba "perdiendo" porque los jóvenes no lo apreciaban suficientemente, $y$, a su juicio, tampoco se veían estimulados a practicarlo. En un documental que realizó Zanada a mediados de la década del `80, un grupo de milongueros y milongueras mayores expresaba:

"Es que uno quiere que el tango siga viviendo (...) y no nos respalda nadie, no tenemos ningún

\footnotetext{
10 Por milonga nos referimos al espacio físico y convencionalizado en donde la gente se reúne a bailar tango (así como se bailan en menor medida otros géneros musicales como la milonga propiamente, el tango vals y en ocasiones también folclore, tropical, jazz entre otras músicas). A su vez, aquellos que frecuentan estos lugares se los denomina milongueros. Estos eventos suelen realizarse en salones, sociedades de fomento o en clubes sociales y deportivos ubicados tanto en los barrios como en la zona del centro de la ciudad. Las milongas generalmente funcionan un día a la semana y su realización depende del "organizador", persona que se encarga y actúa como responsable en la organización del evento.
}

apoyo. Pero lo estamos apoyando nosotros, los pocos que quedamos (...) nosotros mismos, estos que estamos acá podemos difundir el tango por las provincias y se mueren viendo bailar un tango. Porque no lo saben. No tenemos necesidad de ir a Europa. ¿Por qué vamos a ir a Europa? ¿A ver, por qué? (...) Porque, si llegara un momento en que desaparecemos nosotros, el día de mañana ¿Quién va a bailar el tango?" (Film documental Tango Baile Nuestro - 1987)

Vemos en esta narrativa, cómo la recuperación y la valorización del tango es explicada en oposición a otras interpretaciones que presuponen el "éxito" del tango en Europa. En el año 1990 el mismo Juan Carlos Copes ${ }^{11}$ se refería a esta polémica diciendo:

\begin{abstract}
"Había gente muy moralista que pensaba que el tango debido a sus orígenes no podía ser del acervo popular. Al tango le han metido muchas puñaladas, pero sigue y sigue. Y marginado: fue, es y será. A pesar de sus triunfos, como el boom de Broadway con Tango Argentino en el '83 y el movimiento de bailarines hacia el exterior. Países importantes piden el tango danza, pero sigue marginado en su lugar de nacimiento, en Buenos Aires, en el Río de la Plata, en la Argentina. (...) Ahora se esta volviendo un poquito al baile" (en Azzi 1991: 25).
\end{abstract}

Lo que nos interesa enfatizar aquí es que esta referencia temprana al espectáculo "Tango Argentino" que menciona Copes, con el transcurso del tiempo se convertirá en un relato dominante de lo que designaremos como la vuelta del tango. En especial, como veremos, a través de la construcción del relato de "Tango Argentino" se advierte una especie de explicación causal (Ochs 2000: 295) a partir de la cual se interpreta que el interés actual por el baile a nivel local, nacional e internacional estaría signado por la trascendencia del mismo en el extranjero. Tengamos en cuenta que, con el correr de los años el espectáculo de "Tango Argentino" pasó a transformarse en un relato público poseedor de un argumento propio, relato que circulará reiteradamente dentro del ámbito de los milongueros y bailarines del tango de Buenos Aires. En definitiva, este relato dominante vigente hoy en el imaginario de distintos actores, especialistas y allegados al tango (milongueros, bailarines, historiadores, periodistas) reconocerá a "Tango Argentino" como un suceso paradigmático, una especie de "bisagra" entre dos épocas:

"Tango Argentino fue la bisagra de toda esta historia. De eso no cabe duda, seguro. Y como

\footnotetext{
11 Bailarín y coreógrafo de tango con más de 50 años de profesión y 80 de edad, es considerado en la actualidad, por su repercusión y permanencia, uno de los bailarines más prestigiosos y emblemáticos del tango danza en la Argentina.
} 
ha pasado con otras historias en el tango, porque ha pasado, tuvo una repercusión internacional y después volvió acá. Es decir, un poco llevado porque Madonna bailaba el tango y que sé yo, Hollywood quería bailar tango (...) Cosa que ya ha pasado otras veces ¿no? Que el tango tenga éxito en Europa o en Estados Unidos, en el exterior y entonces venga un rebote acá con el tango..." (Entrevista a Luís Tarantino, 2/4/08 - en Maronese 2008: 46).

“Pero Tango Argentino acabó por ser mucho más que un éxito teatral fuera de lo común (...) impulso el renacimiento del género en su manifestación de baile de pista y en una escala que ha llegado a ser planetaria. Si hoy pueden encontrarse "milongas" en Verona o en Moscú, que las hay; más aún, si en Buenos Aires (adonde el espectáculo llegó exactamente diez años después de su estreno original) el tango abandonó los reductos en los que resistió durante décadas y amplió sus horizontes, el responsable es Tango Argentino" (Laura Falcoff 2008: 386).

Advirtamos que esta "gesta"12, que se enfatiza en la voz de dos influyentes periodistas, sobre la vuelta del tango es análoga, como ya mencionamos, a un relato preexistente vinculado a la aceptación y el reconocimiento del tango en su primer período de consolidación en la Argentina. Este relato asume que el tango a lo largo de toda su historia estaría marcado por un mismo proceso cíclico que se repite, sea tanto a comienzos como a fines del siglo $X X$, sosteniendo que el tango -en este caso el baile- requiere para ser apreciado y reconocido como práctica cultural local su previa aprobación en los países centrales o hegemónicos. En otras palabras, como aludimos anteriormente, el tango para salir de su condición de marginalidad primero debe trascender en París, Europa y Estados Unidos para luego poder ser una práctica culturalmente legitimada a nivel local ${ }^{13}$.

Siguiendo a Ochs, los relatos están relacionados con

\footnotetext{
12 Añadamos que el carácter de hazaña y de heroísmo que suele acompañar a este relato de "Tango Argentino" incluye un marco contextual plagado de obstáculos y situaciones hostiles que lo destinaban al fracaso y que, no obstante ello, logró sortear: la incredulidad del entorno, la indiferencia de los empresarios y la falta de apoyo estatal local, la carencia de un contrato así como un largo viaje de 36 horas dentro de un avión militar del ejército en el que viajó a París la compañía completa del espectáculo. Cabe aclarar que este apoyo oficial por medio de un avión militar fue sumamente precario, teniendo en cuenta que los miembros de la compañía debieron viajar en pésimas condiciones "aprovechando" un viaje en el que se llevaba un misil para reparar a Francia. Ver Del Mazo y D'Amore (2001: 115).

13 Cabe destacar que este relato soslaya uno de los momentos de mayor popularidad y creación artística que experimentó el tango en el Río de la Plata a mediados del siglo XX (1935-1955). Recordado hoy como una "época dorada", esta etapa estuvo circunscripta al aislamiento que produjo la coyuntura política de la II Guerra Mundial (Pelinski 2009: 103).
}

"sucesos dignos de mención", esto es, situaciones que se apartan de lo ordinario o de lo esperado y cuyo objetivo a menudo "(...) es la evaluación moral de un hecho acaecido, de una acción o de un estado psicológico en relación con una serie de acontecimientos" (2000: 282). De este modo, para dicha autora todo relato supone un punto de vista particular, pone en juego una interpretación que establece juicios de valor en tanto representa una versión selectiva sobre sucesos del pasado. Cabe entonces preguntarse ¿Qué está connotando el relato de "Tango Argentino"? ¿Quiénes lo representan y qué circunstancias o contextos organizan a este relato? ¿Qué otros acontecimientos y/o agencias discursivas esta invisibilizando? ¿Qué paradojas o tensiones nos permite pensar?

\section{"Tango Argentino" y el relato sobre la vuelta del tango}

En principio, veamos más específicamente en qué consistió "Tango Argentino". El espectáculo fue creado y dirigido por el escenógrafo Claudio Segovia y el productor Héctor Orezzolli. Se estrenó por primera vez en el Teatro de Chatelet de París el 13 de noviembre de 1983, aunque en aquel momento sus creadores y protagonistas artísticos no preveían las respuestas y posteriores derivaciones que tendría el espectáculo. Por su parte, sorpresivamente "Tango Argentino" fue recibido con gran entusiasmo y aceptación en la ciudad parisina, por lo que su gran interés y repercusión permitió que llegara a presentarse posteriormente en el teatro City Center de Broadway (New York) en el año 1986 para luego realizar giras por distintas ciudades del mundo. Finalmente, tras nueve años en cartel en el extranjero, el espectáculo llega a Buenos Aires por primera y única ${ }^{14}$ vez recién en el año 1992, estrenándose durante un corto período (doce funciones) en el teatro Gran Rex y contadas ocasiones en el teatro Lola Membrives.

Integrado por un elenco de más de treinta artistas en escena, "Tango Argentino" mostraba la historia del baile a partir de varios actos protagonizados por parejas de bailarines que diferían entre sí en edad, aspectos físicos, estilos y personalidad en el baile. El espectáculo era musicalizado por una orquesta en vivo que, junto a distintos cantantes, ejecutaban un repertorio variado de tangos clásicos. Asimismo su puesta en escena hacía uso de una cuidadosa iluminación, escenografía y elección de vestuario. Fundamentalmente, desde el punto de vista sus creadores, la idea original e innovadora del espectáculo fue intentar reflejar sobre un escenario a la "genuina raíz porteña" del tango. Como afirma el productor artístico de esta compañía "Lo que hicimos con el espectáculo fue llevar a escena el tango en estado puro. Tomamos un arte popular que existe en la vida, una creación que habían hecho los argentinos y que estaba marginada en

\footnotetext{
14 Recientemente el espectáculo ha sido reestrenado en Buenos Aires el 19 de febrero de 2011 -de manera pública y gratuita- en plena Av. Nueve de Julio (frente al Obelisco) bajo el auspicio y la producción de la actual gestión del Gobierno de la Ciudad (Mauricio Macri).
} 
el 83'" (Claudio Segovia - Diario La Nación - Espectáculos - 31/08/03). A ello Segovia agregará:

"No lo he dicho yo sino son palabras de Don Enrique Cadícamo:- El tango en el año 1983 era un recuerdo, y fue ponerlo en el mundo para que empezara una verdadera ola de pasión por él. Pienso que desde la muerte de Gardel había un gran vacío. En el mundo se conocía la música y el canto, pero no la forma argentina de bailarlo, habían visto un baile de tango europeo, español o norteamericano." (Entrevista, Revista el Tangauta $N^{\circ} 146$ - 2006)

\section{"A partir de Tango Argentino nace el conocimiento del tango bailado (...). Como espectáculo despertó el interés y el deseo de aprender a bailar. Aquellos que tenían pasión por el baile se pusieron a aprender la danza del tango." (Entrevista, Revista B.A. Tango $N^{\circ}$ 23 - 1996)}

Destaquemos que este paulatino interés del tango en el contexto internacional irá inaugurando un nuevo mercado de posibilidades laborales para distintos "maestros" bailarines profesionales, así como para algunos milongueros semi-profesionales, quienes comenzarán a intentar vivir del tango dando clases y espectáculos, y de este modo, viajarán cada vez más asiduamente al exterior ${ }^{15}$.

Si bien el espectáculo incluyó un conjunto de músicos, intérpretes y cantantes reconocidos ${ }^{16}$, muchos coincidirán en que fue particularmente la danza la que se destacó por sobre los demás aspectos del género (su música o su poética). En la opinión de un integrante del elenco de baile:

“Tango Argentino era un espectáculo con mucho baile (...) cuando la gente vio bailar de esa forma y cuando vio que los bailarines no éramos chicos de 20 años, rubios con ojos celestes, sino que éramos gorditos, petisos o pelados, entonces dijo: nosotros podemos bailar también (...)" (Eduardo Arquimbau, en Maronese 2008: 46).

Advirtamos que, ya desde el momento del lanzamiento de "Tango Argentino" en el contexto internacional, el valor agregado o el interés por el baile del tango estuvo muy

\footnotetext{
15 Entre algunos de estos "maestros" milongueros que viajaran frecuentemente se destacan Juan Carlos Copes, Antonio Todaro o "Pepito" Avellaneda, entre otros.

16 El espectáculo reunía a algunas experimentadas parejas de baile argentinas entre las que se destacaron Virulazo y Elvira, Copes y Nieves, Nélida y Nelson, Mayoral y Elsa María, Gloria y Eduardo, María y Carlos Rivarola, Los Dinzel. A su vez, en el elenco de los intérpretes y músicos estuvieron Roberto Goyeneche, Horacio Salgán-Ubaldo De Lío, Osvaldo Berlingieri, Raúl Lavié, el Sexteto Mayor, Jovita Luna, Elba Berón y Alba Solís, entre otros.
}

asociado no tanto a las destrezas acrobáticas o técnicas de los bailarines, sino a un modo específico de baile que este espectáculo mostraba como propio de la Argentina y del Río de la Plata. Es decir, "Tango Argentino" no solo visibilizó y espectacularizó en el contexto internacional un tango diferenciado por su raíz local y porteña, sino que a través de su novedoso plus de "autenticidad" ponderó y dio reconocimiento sobre un escenario teatral a algunos de los más consagrados bailarines milongueros (en su mayoría profesionalizados) y sus diversas modalidades coreográficas identificadas con Buenos Aires y sus milongas, es decir, lo que Segovia más arriba caracterizó como "llevar a escena al tango en estado puro".

Sin embargo, y no obstante la profunda aceptación pública en torno a este relato de "Tango Argentino", simultáneamente circulan en Buenos Aires otras versiones narrativas sobre la vuelta del tango. Por su parte, algunos actores (profesores, alumnos, bailarines, milongueros/as) han considerado que aquello que influyó en el interés por el baile a nivel local estuvo más relacionado con el contexto de regreso a un gobierno constitucional, lo cual en particular se expresó en el baile a través de que:

"... De repente, surgió una especie de optimismo colectivo y mucha gente se atrevió a hacer lo que tenía ganas. Algunas de esas personas empezaron a bailar tango y se dio una mezcla muy positiva entre viejos milongueros, jóvenes que se acercaron por curiosidad y estudiantes de danzas. Yo lo viví de cerca porque en los '80 conseguí con esfuerzo que me aprobaran un curso gratuito en el Centro Cultural General San Martín. El primer día ya había 400 personas y hubo gente que se quedó afuera. Tiempo después se empezaron a abrir los talleres de tango en los centros culturales barriales de la entonces Municipalidad." (Olga Besio - Revista El Tangauta No $174-2009)^{17}$

Como indica el relato de esta profesora, a partir del restablecimiento del orden constitucional irán surgiendo distintos ámbitos para la enseñanza, transmisión y práctica del baile dentro de la ciudad de Buenos Aires. Algunos de estos espacios, que se ofrecerán a modo de "clases", "talleres" y "prácticas", representarán una significativa vía alternativa para el ingreso de distintos actores sociales que se aproximaban por primera vez al tango por aquel entonces. En este sentido, si como mencionamos anteriormente, algunos bailarines y milongueros antiguos esgrimían que la juventud por aquel entonces parecía no estar interesada por el tango que ellos ejecutaban, por otro lado, como veremos, a partir de algunos nuevos

\footnotetext{
17 Olga Besio es bailarina y profesora de tango. Trabajó como docente durante 20 años acompañada por su pareja Gustavo Naviera. Por su parte, Gustavo Naviera -en tanto uno de los más prestigiosos bailarines en el mundo actual del tango- comienza a tomar sus primeras clases de tango desde muy joven en 1981 con Rodolfo Dinzel. Junto a su compañera Olga empezarán a dar clases de baile en los inicios de los años 80.
} 
ámbitos ubicados relativamente por fuera de la "mirada" y la evaluación estricta de la ortodoxia milonguera, comenzará a verificarse una incipiente incorporación e interés por parte de nuevos actores, muchos de ellos jóvenes, en el baile. A continuación abordamos esta revitalización de la práctica del baile a partir de una serie de narrativas que irrumpen, en cierto modo, descentradas respecto del suceso de "Tango Argentino".

\section{Nuevos espacios, actores y disputas en torno al baile de tango en Buenos Aires}

En el marco de la transición democrática, a partir del año 1984 la entonces Secretaría de Cultura de la Municipalidad de Buenos Aires crea una serie de actividades y programas culturales. Surge de este modo el "Programa Cultural en Barrios" el cual implementa y pone en marcha Centros Culturales en distintos barrios de la ciudad en los que se realizan, entre otras actividades, talleres de tango para aprender a bailar. El antropólogo Fernando Rabossi (1997), en su tesis de grado, analizó dicho Programa y allí describe algunas de sus experiencias personales en las clases del taller de tango que se realizaban en el centro cultural Fortunato Lacámara, ubicado en el barrio de San Telmo. Según Rabossi, el taller de tango de este centro cultural funcionó de manera continua desde el año 1985 (su indagación culmina en 1995) con una demanda y concurrencia permanente de personas inscriptas. Rabossi describe sus primeras "sensaciones" cuando se acerca a este centro cultural, recordando su participación en el taller de tango del año 1988:

\begin{abstract}
“En el centro [cultural] sentía que pasaban cosas que en otros lados no pasaban, o al menos no con las características que allí se daban. Se podía aprender a bailar tango, algo de lo que hasta ese momento nunca había sabido de dicha posibilidad. Después sí, uno se enteró que había profesores, academias, pero hasta entonces nunca había escuchado de la posibilidad de aprender a bailar tango. En el centro cultural empecé a descubrir otras cosas: gente que bailaba muy bien, lugares de baile, y demás." (1997: 25)
\end{abstract}

Sumado a todos estos aspectos, subraya que al centro cultural asistía gente de distintas edades y sectores sociales (chicos, adolescentes, jóvenes, madres, padres, trabajadores, empleados, jubilados). Asimismo, destaca que allí se conocían y creaban grupos de amistad, se establecían relaciones interpersonales, así como se organizaban fiestas los fines de semana o salidas a bailar con la gente del taller a salones bailables de la zona (1997: 15). Rabossi también describe algunos de los motivos por los cuales las personas se acercaban al taller de tango:

“... 'Tuve que esperar que se muriera mi esposo para salir a bailar', y esta frase que me dijo una de mis compañeras también se la escuché a otras de ellas. Muchos señalan al taller como el lugar para "desenchufarse" después del trabajo o de las actividades cotidianas. Pero, ¿Por qué el tango? Están aquellos que siempre les gustó y nunca supieron bailar; y en este sentido el taller les permite hacerlo de una manera legítima: el taller es un espacio de aprendizaje y allí los errores son permitidos. También están aquellos para los cuales el taller constituye un espacio de práctica, de corrección y control de lo que ya se sabe y de incorporación de algún nuevo paso o figura. La gente más joven apuesta a aprender algo nuevo que tiene sus méritos precisamente en su aparente "vejez". Claro que transcurrido un tiempo, muchos se dedican de manera sistemática y algunos intentan "profesionalizarse". El salto siguiente al taller es ir a bailar a alguna milonga o salón, el cual marca el compromiso que asume cada uno con esto de aprender a bailar el tango. En el taller se forman grupos que luego salen a bailar los fines de semana o al menos cada tanto." (Rabossi 1997: 86)

Como se observa en esta descripción, varios factores incidían en el hecho de que el público local se acercara y asistiera a estos lugares. Destaquemos que muchas de estas clases eran gratuitas y funcionaban en espacios abiertos, públicos y de fácil acceso que solían funcionar físicamente en escuelas o centros educativos municipales. Junto a ellas también existieron pequeños emprendimientos en otros ámbitos (no necesariamente dependientes de la municipalidad) como locales partidarios, sociedades de fomento y clubes sociales. En muchos casos, estos nuevos espacios se caracterizarán por estar menos influidos por las exigencias y las presiones de algunos grupos de antiguos y establecidos milongueros, y sus evaluaciones sobre los "correctos" modos de ejecución del baile de tango.

Tengamos en cuenta que el intercambio generacional y el arribo de nuevos performers o bailarines a las pistas de algunas de las milongas más tradicionales producirá distintos tipos de conflictos y controversias. Estas tensiones perduran en la memoria de muchos milongueros y milongueras contemporáneos que comenzaron a bailar entre mediados y fines de la década del '80, quienes en tanto "principiantes" sin mucha experiencia intentaban participar de los ámbitos de baile de las milongas tradicionales de Buenos Aires. Veamos algunos testimonios:

“... había milongas donde no podía bailar cualquiera, estas de Villa Urquiza, yo iba y me quedaba sentada hasta las dos de la mañana, no nos animábamos a salir, iba con mi compañero y nos quedábamos sentados en la mesa mirando como bailaban los que sabían. Recién a las dos o tres de la mañana cuando el ambiente se aflojaba... Porque había un clima de tensión en 
esas milongas. Te estoy hablando del Sunderland, de la de Parque Patricios, del Club Sin Rumbo. Nadie se atrevía a tirar un tanguito al club Sin Rumbo teniendo dos meses de estudio, nadie. Cuando ya estaba un poco mas avezada, sí. Siempre con mucho respeto, porque ahí estaban los grandes, estaban los "grossos", vos tenías que sentarte y mirar. Tenían sus reglas estrictas, no podías empujar a nadie, no podías rozar con el codo a nadie, no podías hacer figuras, tenías que mantenerte en la rueda que giraba sin pasarse. Tenías que realmente manejar el espacio, y el tiempo musical. Entonces no nos animábamos mucho. Había mucho respeto por la gente mayor. íbamos tremendamente empilchados como hacían los viejos. Muchísima gente mayor. Que eran los que te transmitían esa cultura tanguera. El salón Canning también. En Canning no bailaba cualquiera, después las milongas de Gustavo [Naviera] ahí si íbamos a practicar a entrenar, eran más relajadas." (Entrevista a Marisa Calcagno $18 / 12 / 08)$

Otra informante afirma durante una entrevista:

“G: En los centros culturales (...) la gente que iba, era gratuito o pagábamos muy poco y entonces los que iban era gente joven. Me di cuenta que éramos los únicos jóvenes cuando empecé, cuando me llevaron por primera vez a Villa Urquiza, ahí eran todos, todos, todos gente grande, en Villa Urquiza o en Canning o en Sin Rumbo. Ahí me di cuenta que era un mundo absolutamente diferente, denso con mucho código y que no era así tan divertido como el centro cultural que uno bailaba con uno, otro bailaba con otro, era mucho más "free". Entrar en la milonga Sin Rumbo y... era denso, muy denso. Muy interesante, con el tiempo, pero tenías que pagar derecho de piso. $\mathrm{H}$ : ¿Como mujer estas diciendo?

G: No, como joven. Entonces los jóvenes de esa época no éramos muchos..." (Entrevista a Graciela González - 3/12/08)

Ahora bien, a partir de estos relatos podemos deducir las dificultades y obstáculos que afrontaban aquellos principiantes que buscaban incursionar en algunos de los circuitos más tradicionales de baile de Buenos Aires. Por una parte, muchos de los que habían comenzado a dar sus primeros pasos desde ámbitos asociados a "talleres", "clases" o "prácticas" experimentarán distintas formas de intimidación y rechazo. De este modo, describirán y recordarán a las milongas durante estos primeros acercamientos como lugares en donde algunos milongueros y milongueras mayores solían descalificar a los principiantes no habitúes de las mismas. En otros casos, las generaciones de jóvenes que asistían a estos ámbitos mencionarán el carácter "difícil", "cerrado" y "rígido" de algunos de estos experimentados milongueros y milongueras, así como connotarán el clima hostil, jerárquico y competitivo que se vivenciaba en estas milongas tradicionales. Por ello, en algunos casos, la táctica utilizada por estas principiantes será que alguien las "apadrine", o bien lograr amistad con alguien que goce de reconocimiento dentro de la milonga para poder ser aceptadas por sus habitúes:

"Puppy [Castelo] fue el que me llevó a Sin Rumbo, ahí entré como apadrinada por él, entonces mi pago de derecho de piso no fue tan fuerte, en realidad, pero para los hombres jóvenes sí fue mucho más fuerte." (Entrevista a Graciela González - 3/12/08)

"Como yo empecé a ir a las milongas con él [Miguel Ángel Zotto] no pasé esa instancia que sucede que cuando vos vas a bailar y la gente no te conoce, el hombre no te saca a bailar, no pasé por ese momento porque yo iba con mi compañero, entonces bailaba con él. Eso antiguamente, cosa que ahora no pasa, había toda una especie de código sagrado de que los que entraban en una pista de baile tenían que saber bailar, o sea, no había lugar para los principiantes en una pista de baile..." (Milena Plebs - Entrevista pública durante el campeonato mundial - 24/08/07)

En suma, a partir de este panorama de disputas, atracciones y rechazos en los ámbitos del baile se consolidará un proceso de incorporación de nuevos actores que irá derivando en un progresivo repoblamiento de las milongas porteñas (Carozzi 2005). De este modo, vemos que en un terreno de fuertes controversias, ya desde mediados de la década del '80, empieza a verificarse un incipiente intercambio generacional que implicará un paulatino interés por el baile dentro del contexto de la sociedad local de entonces. Simultáneamente, el arribo de estos nuevos actores instaurará sentidos y prácticas emergentes creándose un campo de disputas en torno a los criterios de autoridad que organizan a estos espacios de relaciones. Como observó Bourdieu respecto de los conflictos generacionales:

"Los conflictos generacionales oponen no tanto clases de edad separadas por propiedades de naturaleza, sino habitus producidos según modos de generación diferentes, es decir, por condiciones de existencia que, oponiendo definiciones diferentes de lo imposible, de lo posible y de lo probable, hace que los unos experimenten como natural o razonable unas prácticas o aspiraciones que los otros sienten como impensables o escandalosas, y a la viceversa." (2007: 100, nota al pie)

En particular vemos que, a diferencia del período 
anterior, comienza a notarse un involucramiento en el aprendizaje del baile de nuevos participantes, muchos de ellos provenientes de sectores de las clases medias porteñas, del mismo modo que algunos se acercarán a partir de una práctica anterior en otras danzas (clásicas, contemporáneas, folklore). Podríamos afirmar que, siguiendo a Bourdieu (1990), las narrativas mencionadas más arriba explicitan las controversias y las lógicas en tensión que se estaban configurando dentro del campo social y cultural del baile y las milongas porteñas. Por una parte, aparecían muchos jóvenes, que en tanto nuevos actores que recién empiezan y llegan al espacio de relaciones del baile, comienzan a participar de actividades y clases en lugares como centros culturales y ámbitos no tradicionales. Por otro lado éstos, por lo general, serán desaprobados por aquellos que ya estaban, y que poseían mayor reconocimiento, trayectoria y acumulación de un capital específico dentro del campo, representados tanto por los milongueros profesionalizados como por los amateurs. En general, a estos nuevos performers se los acusará de realizar distintas prácticas heréticas o incorrectas, sea por desvirtuar las modalidades de baile deseables o los habitus dancísticos de los milongueros establecidos, así como por no "respetar los códigos" o los comportamientos tradicionales de la milonga, de modo que, algunos calificarán peyorativamente y estigmatizarán a estos nuevos bailarines y participantes de la milonga.

\section{"Tango Argentino" y su relato consagratorio}

Retornando al relato épico sobre "Tango Argentino", vemos que algunas narrativas personales de docentes y alumnos de entonces, revelan el carácter sobrevaluado del rol que se le atribuye a éste espectáculo de orden internacional en la recuperación o revitalización del tango en el contexto local. A su vez, algunos docentes diferenciarán aquellos actores que protagonizaron este proceso de crecimiento del baile "desde el extranjero" y aquellos que lo hicieron a nivel local, entendiendo que el interés en Buenos Aires por el baile antecedió al éxito de este espectáculo en el extranjero:

"Tango Argentino fue un hito en el exterior, pero no acá, donde se lo conoció varios años después. Tampoco me cierra la hipótesis de que haya repercutido tanto desde afuera porque en los '80 no venían tantos extranjeros a Buenos Aires. Es más: recuerdo que cuando acá ya se había producido la explosión de interés por el tango, en los diarios no había salido ni siquiera una mención a Tango Argentino. Eso no le quita méritos a Tango Argentino. Hay quienes hablan desde sus experiencias en el exterior, yo hablo de lo que viví acá." (Olga Besio - Revista El Tangauta No 174 - 2009)

Evidentemente aquellos argentinos y porteños que tuvieron la posibilidad de ver en vivo en el extranjero a
"Tango Argentino", esto es participando como público presencial de su representación, ha sido un porcentaje muy menor. Advertimos así que el elevado valor que se proyecta sobre el espectáculo presupone el hecho de que éste haya sido consagrado por un público ligado a las grandes metrópolis culturales (París, New York). Por lo que la legitimación de este espectáculo en el contexto local cobra fuerza a través del relato contado por algunos de sus protagonistas (directores, bailarines, músicos, cantantes, etc.) en tanto voces autorizadas en la narración de esta historia. A su vez, nótese que la construcción de una narrativa que sobreestima a "Tango Argentino" contribuye a legitimar el lugar de autoridad consagrada de algunos de los emprendedores y protagonistas de este espectáculo, los cuáles a modo de "héroes culturales" serán reconocidos como los principales representantes y agentes en esta última vuelta del tango.

Como describimos anteriormente, la condición de verdad de los sucesos narrados por este relato, se reforzará con un relato análogo que lo precede en tanto historia canónica del género. Este entiende que el tango, más allá del paso del tiempo y los cambios de condiciones históricas, requiere para dotarse de autentificación local de una valoración positiva en el extranjero. Como afirmó Rodolfo Dinzel, quien fuera integrante del elenco de bailarines de "Tango Argentino": "para que el tango fuera bailado a menos de un kilómetro de aquí, hubo que ir a Europa y volver. Es la paradoja" (en Azzi 1991: 35). Si bien esta especie de "paradoja" en la historia del tango supone, como todo relato, un punto de vista, una versión y un juicio moral sobre lo narrado. Por el contrario, mencionamos que algunos no protagonistas del espectáculo de "Tango Argentino" cuestionarán el mensaje de este relato dominante, postulando una significativa demanda vinculada a una reorientación y un interés por el baile a partir de actores y eventos que se ubican en el nivel local. Estas narrativas parecen indicar que los factores que colaboraron y afectaron la práctica del baile no estuvieron tan relacionados, al menos en un comienzo, con la aprobación y el "éxito" del tango en el extranjero, ni tampoco con el interés meramente turístico del mismo.

Hasta aquí, señalamos cómo distintas memorias interrelacionadas narran y tradicionalizan diferencialmente esta última vuelta del tango, por un lado, valorándolo positivamente a partir de su exportación y resonancia internacional y, por otro, enfatizando que la práctica del baile estuvo más asociada con la afirmación del mismo sobre la base de una revalorización acaecida por actores locales. Vimos que el punto de vista que sostiene el relato dominante supone una versión que selecciona y olvida ciertos sucesos significativos al mismo tiempo que pondera la excepcionalidad y el carácter memorable de otros, y así, omite el rol de distintos grupos, actores y sucesos locales en esta dinámica cultural compleja. De este modo, algunos pondrán en tela de juicio la versión 
dominante modificando la trama argumental del relato, cuestionando y revisando la construcción de sentidos de verdad sobre estos sucesos. Con esto no queremos negar la repercusión que asistió en su momento al espectáculo "Tango Argentino", ni tampoco minimizar la atracción por el baile que pudo haber provocado en algunas personas, sino más bien reflexionar sobre la complejidad de estos procesos culturales, del mismo modo que problematizar las distintas lógicas en tensión que los guían. Esto es, advertir cómo un relato "consagratorio" puede invisibilizar y minimizar procesos culturales que, no obstante, parecen haber sido muy significativos para la vuelta del tango.

Retomando la perspectiva planteada al inicio de este trabajo entendemos que las narrativas difícilmente puedan ser abordadas como manifestaciones aisladas de sus contextos históricos específicos. De esta manera las narrativas no son dispositivos pasivos de descripción o representación de "hechos" del mundo sino que, por el contrario, éstas se organizan y adquieren sentido a partir de los contextos en los que se construyen, y así forman parte del propio mundo narrado. Particularmente, como afirma Ochs (2000: 280) cuando elaboramos narraciones referentes a sucesos pasados éstas son también narraciones sobre el presente y el futuro. En nuestro caso -independientemente de la polémica de cuál fue el grado de incidencia que tuvo el espectáculo "Tango Argentino" como desencadenante para el resurgimiento del tangoentendemos que esta versión narrada cobra particular eficacia simbólica a la luz del auge actual que vive el tango enmarcado en un proceso de internacionalización del mismo. Como hemos señalado en trabajos anteriores (Morel 2009, 2011a) en la actualidad el tango bailado afirma un renovado valor en tanto práctica local e internacional, del mismo modo que se ha transformado en un poderoso recurso para la promoción económica y el desarrollo turístico de Buenos Aires. Por consiguiente, hallamos que la condición de verdad de dicho relato se retroalimenta de las actuales circunstancias favorables que ubican al tango-danza en el mercado transnacional, circunstancias que fueron emergiendo paulatinamente a partir de la década de los '90 y que se consolidarán fuertemente a comienzos del siglo XXI. Ya en el nuevo milenio esta resonancia internacional, junto a la reafirmación turística de Buenos Aires como la "meca" del tango, se ira intensificando para culminar en la reciente declaratoria, por parte de la UNESCO, del tango como Patrimonio Cultural Inmaterial de la Humanidad.

\section{Conclusiones}

Al analizar las narrativas de diferentes actores y protagonistas que interpretan la revitalización del baile a nivel local en el contexto de la década del '80, observamos distintos posicionamientos ante una concepción hegemónica o canónica del tango. Para los que aseveran la importancia del espectáculo de "Tango Argentino" este hito será el que justificará la resonancia y el impulso del baile, tanto a nivel local como internacional. Como vimos, este relato no sólo pondera diferencialmente los "hechos" (esto es si hubo o no antes del éxito de "Tango Argentino" una demanda o interés a nivel local por el baile) sino que el mismo reproduce (y por tanto reafirma) el mito de la consagración del tango en las metrópolis hegemónicas para su aceptación en el lugar de origen. De este modo, el relato consagratorio del tango a partir de las metrópolis centrales tenderá a velar diversas prácticas y experiencias locales, al mismo tiempo que su trama argumental refuerza una posición de dependencia del tango que lo (re)enmarca en una relación de tipo imperio/ colonia (Savigliano 1995: 137). En todo caso, la narrativa en torno a "Tango Argentino" evidencia -nuevamenteuna genealogía para el tango en la que se desplaza e invisibiliza la intervención y la participación de distintos actores locales frente a los globales.

Ahora bien, si por un lado, desde una posición hegemónica predomina una narrativa homogenizadora, coherente y cíclica en torno al tango, por otro lado, relevamos distintas memorias personales que aparecen como voces que enriquecen, complementan, matizan así como disputan la imposición de una narrativa unificadora. Al respecto, abordamos etnográficamente algunas de estas narrativas observando las prácticas y lógicas periféricas que emergieron a la sombra de este relato hegemónico, señalando a su vez, cómo estas prácticas se producen con cierta autonomía relativa respecto de los discursos referidos a los centros culturales metropolitanos. Advertimos que dicho relato hegemónico conllevará distintas reacciones y respuestas dialógicas (Bajtín 1992: 284) por lo que otras narrativas, frente al énfasis de estas interpretaciones entenderán que dicha posición escamotea u oculta sucesos significativos ocurridos en Buenos Aires en relación a la práctica del baile. Así pues, el relato de "Tango Argentino" que se contextualiza en el presente, y que a su vez se construye y encadena con otras "voces" o enunciaciones históricas, establece una condición dialógica que entrevé posibles respuestas al mismo. Como señaló Bajtín "el enunciado es un eslabón en la cadena de comunicación discursiva y no puede ser separado de los eslabones anteriores que lo determinan por dentro y por fuera generando en él reacciones de respuesta y ecos dialógicos (...)" (1992: 283)

Por otra parte, al abordar distintas narrativas de actores locales observamos un núcleo de temas y problemas específicos que acompañaron a esta última vuelta del tango. En relación a las transformaciones acaecidas a nivel local, a través de la trayectoria de algunos bailarines y participantes que incursionaron en la práctica del baile durante la década del '80, describimos la emergencia de ámbitos relativamente novedosos, como por ejemplo "centros culturales", "talleres" o "prácticas", del mismo modo que observamos las incipientes y conflictivas interrelaciones que establecían estos nuevos actores con espacios milongueros más tradicionales. Sobre la base 
de estas narrativas, relevamos algunas nuevas formas de enseñanza, apropiación y práctica que fueron surgiendo y que colaboraron en la multiplicación, diversificación y reproducción del baile a nivel local, en paralelo a la formación de incipientes espacios y marcos político culturales. Asimismo, se observa un recambio generacional que implicará el pasaje o la reconfiguración de un modo de reproducción cultural del baile marcadamente cerrado, por momentos percibido como autoritario y ortodoxo, a uno más participativo y abierto, en el que comienzan a integrarse con un rol mucho más protagónico y activo mujeres, jóvenes y distintos sectores sociales, en particular las clases medias porteñas.

En definitiva, por todo lo expuesto consideramos relevante abordar desde los estudios antropológicos no solo los procesos de diseminación que reviste el tango a partir de sus "viajes de exportación" (Garramuño 2007), las reterritorializaciones del tango "nómade" alrededor del mundo (Pelinski 2009) o los efectos que ejercen las "metrópolis centrales" sobre las culturas periféricas (Savigliano 1995), sino también articular estas problemáticas y procesos culturales en relación a las transformaciones específicas que experimenta el tango en su propio lugar de origen, esto es, los propios extrañamientos, encuentros y conflictos que se producen a partir de su contexto local. En nuestro caso prestar atención a estos procesos de cambio nos permitió comprender, en parte, la densidad de tensiones y significaciones en pugna que entrama el tango en Buenos Aires. De esta manera, podremos desarmar cierto discurso dominante, el cual suele operar como metalenguaje de los valores y las experiencias de los dominados (Grignon y Passeron 1991: 64), desnaturalizando así el relato canónico que aún se impone sobre el tango.

Buenos Aires, febrero de 2012

\section{Agradecimientos}

El presente trabajo es una reformulación de uno de los capítulos de mi tesis doctoral (2011). Quisiera agradecer los comentarios y las lecturas críticas de las compañeras María Julia Carozzi, Belén Hirose, Guadalupe Gallo, Sayuri Raigoza y Denise Osswald, integrantes del Núcleo de Estudios en Antropología de la Danza del IDAES/UNSAM.

\section{Bibliografía:}

Azzi, M.1991. Antropología del tango. Los protagonistas, Olavaria, Buenos Aires.

Bajtín, M.1992. [1979] El problema de los géneros discursivos. Estética de la creación verbal, pp. 248-293, Siglo XXI, México.

Bourdieu, P. 1990. Algunas propiedades de los campos. Sociología y Cultura, pp. 135-141, Grijalbo, México.
Bourdieu, P. 2007. El sentido práctico, Siglo XXI, Buenos Aires.

Briggs, C., R. Bauman. 1996. Género, intertextualidad y poder social. Revista de Investigaciones Folclóricas 11: 78-108.

Carozzi, M. 2005. La edad avanzada como valor en el tango bailado en Buenos Aires. Revista Cuestiones Sociales y Económicas, III (6): 73-86.

Cibotti, E. 2009. Del encanto al desencanto de una élite, en clave de tango. En Lencina, T., García Brunelli, O., Salton, R. (comp.), Escritos sobre tango. En el Río de la Plata y en la diáspora, pp. 41-54, Centro 'feca, Buenos Aires.

Chertudi, S. 1967. El cuento folklórico. CEAL, Buenos Aires.

Del Mazo, M., A. D’Amore. 2001. Quién me quita lo bailado. Juan Carlos Copes: una vida de tango, Corregidor, Buenos Aires.

Falcoff, L. 2008. Historia del tango escénico. En Historia general de la danza en la Argentina, pp. 371-391, Fondo Nacional de las Artes, Buenos Aires.

Garramuño, F. 2007. Modernidades primitivas. Tango, Samba y Nación, Fondo de Cultura Económica, Buenos Aires.

Grignon, C., J. Passeron. 1991. Lo culto y lo Popular. Miserabilismo y populismo en sociología y en literatura, Nueva Visión, Buenos Aires.

Hymes, D. 1986 [1972]. Models of the Interaction of Language and Social Life. En Gumperz, John y Dell Hymes (eds.), Directions in Sociolinquistics: The Ethnography of Communication, pp. 35-71, Basil Blackwell, Oxford/ Nueva York.

Lamas, H., E. Binda. 2008. El tango en la sociedad porteña 1880-1920, Abrazos, Stuttgart.

Langdon, E. J. 1999. A fixacao da narrativa: do mito para a poetica de literatura oral. Revista Horizontes Antropologicos 12: 13-36.

Lévi-Strauss, C. 1987. La eficacia simbólica. Antropología Estructural, pp. 211-227, Paidos, Barcelona.

Maronese, L. 2008. De milongas y milonguer@s. Comisión para la Preservación del Patrimonio Cultural de la Ciudad Autónoma de Buenos Aires.

Morel, H. 2009. El giro patrimonial del tango: políticas oficiales, turismo y campeonatos de baile en la Ciudad 
de Buenos Aires. Cuadernos de Antropología Social 30: 155-172.

Morel, H. 2011a. "Milonga que va borrando fronteras". Las políticas del patrimonio: un análisis del tango y su declaración como Patrimonio Cultural Inmaterial de la Humanidad. Intersecciones en Antropología 12: 163-176.

Morel, H. 2011b. "Políticas culturales y performance en los procesos patrimoniales. Los casos del tango y el carnaval en la ciudad de Buenos Aires". Facultad de Filosofía y Letras, UBA, Argentina. Tesis de doctorado, Biblioteca de la Facultad de Filosofía y Letras.

Ochs, E. 2000. Narrativa. En Van Dijk, T. (comp.), El discurso como estructura y proceso. Estudios del discurso: introducción multidisciplinaria, pp. 271-303, Gedisa, Barcelona.

Pelinski, R. 2000 [1981]. Decir el tango. Invitación a la Etnomusicología. Quince fragmentos y un tango, pp. 26-42, Akal, Madrid.
Pelinski, R. 2009. Tango nómade. Una metáfora de la globalización. En Lencina, T., García Brunelli, O., Salton R. (comp.), Escritos sobre tango. En el Río de la Plata y en la diáspora, pp. 65-129, Centro 'feca, Buenos Aires.

Pujol, S. 1999. Historia del baile. Emecé. Buenos Aires.

Rabossi, F. 1997. "La cultura y sus políticas. Análisis del Programa Cultural en Barrios". Facultad de Filosofía y Letras, UBA, Argentina. Tesis de Licenciatura, Biblioteca de la Facultad de Filosofía y Letras.

Rosaldo, R. 1989. Análisis de la narrativa. Cultura y Verdad. Nueva propuesta de análisis social, pp. 123-136, Grijalbo, México.

Savigliano, M. 1995. Tango and the political economy of passion. Boulder, Colorado.

Vega, C. 2007. Estudios para los orígenes del tango argentino. Coriún Aharonián (Editor), Universidad Católica Argentina, Buenos Aires. 